\title{
Vocational Decision-Making and Rehabilitation Following Paediatric Traumatic Spinal Cord Injury: An Illustrative Case Study Analysis
}

\section{Murphy G*}

Faculty of Health Sciences, Latrobe University, Australia

*Corresponding author: Murphy G, Faculty of Health Sciences, School of Public Health, Latrobe University, Melbourne, 3086, Australia, Tel: +61394791745, E-mail: G.murphy@latrobe.edu.au

Citation: Murphy G (2013) Vocational Decision-Making and Rehabilitation Following Paediatric Traumatic Spinal Cord Injury: An Illustrative Case Study Analysis. J Case Rep Stud 1(1): 101. doi: 10.15744/23489820.1.101

Received Date: June 28, 2013 Accepted Date: July 29, 2013 Published Date: August 01, 2013

\section{Introduction}

Within traumatic-injury populations, adjustment following the suffering of a permanent impairment such as a traumatic Spinal Cord Injury (tSCI) follows quite a different path (and has quite different longer term participation outcomes) when the individual involved is a child or adolescent, and not an adult. The most influential framework for understanding the factors influencing longer-term outcomes for those with an illhealth condition [1] is a general model applicable to those of any age, and thus demographic factors such as "age at injury" or "age at disease onset" are not specifically depicted in the model of factors influencing injury sequelae, except that they are implicitly contained within one of the two sets of variables (one "Personal", one "Environmental") which are proposed to moderate the longer-term outcomes achieved following the suffering of an impairment of structure or function. While the ICF framework has been most useful to both health researchers and managers of health services, its influence on the particular set of services offered by health and humanservice professionals has been weakened by the fact that, in its original publication of the model, both sets of moderating variables were just listed as blocks of variables with no detail about the major personal or environmental variables exerting most influence - and therefore, by implication, requiring focussed consideration by care planners and deliverers of health services. The case study below of an adolescent who suffered a paraplegia yet subsequently achieved a most successful rehabilitation outcome illustrates the key psychosocial factors (one "personal" and one "environmental") involved in adjusting successfully to major impairment and ultimately achieving a high post-injury quality of life.

\section{Literature review}

Studies of predictors of health outcomes associated with major traumatic injuries have, perhaps understandably, concentrated on identifying the explanatory power of variables from two groups of factors: (a) variables associated with the injury itself, including, particularly, measures of injury severity and of functional independence; and (b) demographic variables. Typical of such studies are those reported by Krause and colleagues [2]. Less common are predictive analyses of the contribution of particular environmental variables or of individual variables that are not demographic (i.e. individualdifference variables such as constitutional optimism, personal control et cetera), such as are reported in the studies of Murphy and colleagues $[3,4]$.

\section{Methodology}

The information contained in this case study did not come from a controlled $\mathrm{N}=1$ design [5] as is required for drawing conclusions with good internal validity. Rather it came from an analysis of a single case, noteworthy because of the high quality of life attained even while living with major disabilities. From studying the case file notes of clinical interviews and reviews held with the individual over the course of more than a decade it was felt that by explicating the processes followed and experiences undergone some useful guides might emerge for those involved in delivering rehabilitation services to those with similar disabling injuries.

\section{Study}

N.S. was a 16 year old, academically capable high-school student when he was involved in a relatively minor motorvehicle accident from which all save he walked away. N.S., however, suffered a lower-level spinal cord injury. At the time of injury, N.S. lived in a regional city, where his family was very well socially integrated. While undergoing his many months of hospital-based rehabilitation, N.S. had a constant stream of visitors (from school, family and the local community) and started to think about career options now that he had mobility limitations that would mean he would be in a wheel-chair for his working life. He formed the idea of becoming a teacher-an occupational goal that he subsequently achieved, along with later marrying a doctoral-level, able-bodied psychologist.

\section{Analysis}

The above snap-shot contains reference to two key factors that the author believes influence the success of the rehabilitation effort for all who have a chronic condition. First, N.S.'s choice of teaching as a career goal was realistic given that he was realistic given that he was a capable student, well prepared for university courses in education. In other words, he had high academic self-efficacy [6] and thus judged teacher training as 
within his capacity. In this regard, he was dissimilar to many of his injured peers who often are from the group of early school leavers and thus are faced with trying to change their career aspirations from labour-intensive occupations to more administrative and/or knowledge-based occupations. Thus, when an agricultural worker, for example, is advised by his allied health worker or community-based Case Manager to think about work with computers, the agricultural worker (besides often not being interested in office work) usually feels that such a role is out of his/her reach. That is they have low "effort-performance expectancy" in the terminology of expectancy-valence theories of motivation $[7,8]$.

The second detail from the above snap-shot that the current author believes is central to longer-term successful rehabilitation is the fact that N.S. was well supported socially. For the overwhelming majority of individuals, social support is crucial to the individual's persisting in pursuit of goals, even in the face of set-backs [9]. N.S.'s social supporters assisted his successfully finishing high school and performing well at university. His residence in a regional city increased his chances of gaining community support [10], which often opens doors to successful management of life problems predictably faced following discharge from hospital - for example relationship problems, friendship problems, health self-management problems, career problems etc.)

\section{Conclusions and Recommendations}

N.S.'s successful post-injury achievements started with his successful return to school, en route to a stable career as a teacher. Many similarly-injured adult peers never return to their pre-injury role nor indeed to the labour force at all [11]. Some of N.S.'s return to his pre-injury (student) role was due to his high degree of academic self-efficacy. Many adult paraplegia sufferers have low self efficacy for return to their pre-injury industry or occupation, or even for successful job seeking for a new career. The other positive factor in N.S.'s situation which the current author believes had a powerful main effect on his subsequent successful rehabilitation was his high level of social support. Social support is crucial to successfully avoiding the post-injury isolation that frequently follows on from tSCI. Further, social support plays a "buffering" role in moderating the effects of various stressors that are predictably encountered when adjusting to life in a wheel-chair [12].

Thus paediatric tSCi is both similar to, and different from, adult
tSCI. In the current author's opinion, the main differences relate to hospital staff and family expectations about the setting to be returned to post-discharge. For the child or adolescent, a return to schooling is the expected post-discharge goal. For the adult with tSCI, there are minimal, conflicting or vague expectations about return to work or return to pre-injury employer - even though return to work has a major health-promoting effect [13], and return to pre-injury employer is the most successful path to labour force participation post-discharge.

The similarities between the paediatric and adult postdischarge experience are related to the individual's selfefficacy and social support. These are the two major influential psychosocial factors impacting on the quality of life achieved following the suffering of disabling injury. Both clinicians and community-based Case Managers need to know about these factors and those services that can enhance both, so as to optimise the post-injury quality of life of all who suffer permanent impairments.

\section{References}

1. World Health Organisation (2001) International Classification of Functioning, Disability and Health (ICF). Switzerland.

2. Krause JS (1992) Employment after spinal cord injury. Arch Phys Med Rehabil 73: 163-9.

3. Murphy G, Brown D, Athanasou J, Foreman P, Young A (1997) Labour force participation and employment among a sample of Australian patients with a spinal cord injury. Spinal Cord 35: 238-44.

4. Murphy G, Middleton J, Quirk R, De Wolf A, Cameron ID (2009) Prediction of employment status one year post-discharge from rehabilitation following traumatic spinal cord injury: an exploratory analysis of participation and environmental variables J Rehabil Med 41: 1074-9.

5. Sidman M (1960) Tactics of scientific research. New York: Basic Books.

6. Bandura A (1986) Social foundations of thought and action The Health Psychology. Englewood Cliffs: Prentice-Hall.

7. Vroom V (1994) Work and motivation. Wiley Publisher, San francisco, USA. 8. Foreman P, Murphy G (1996) Work values and expectancies in occupational rehabilitation: the role of cognitive variables in the return-to-work process. Journal of Rehabilitation 3: 44-8.

9. Murphy G (2009) Using unpredicted vocational outcomes following traumatic spinal cord injury to identify powerful, nove return-to-work barriers and facilitators. Nova Science, New York, USA.

10. Young AE (1999) Spinal cord injury in the agricultural workforce: Rates and Rehabilitation. Monash University, Clayton, Melbourne, Australia.

11. Athanasou JA, Brown DJ, Murphy G (1991) Vocational achievement following spinal cord injury in Australia. Disabil Rehabil 18: 191-6.

12. Cohen S, Wills TA (1985) Stress, social support and the buffering hypothesis. Psychol Bull 98: 310-57.

13. Athanasou JA, Murphy GC (1999) The effect of unemployment on mental health. J Occup Organ Psychol 72: 83-99.

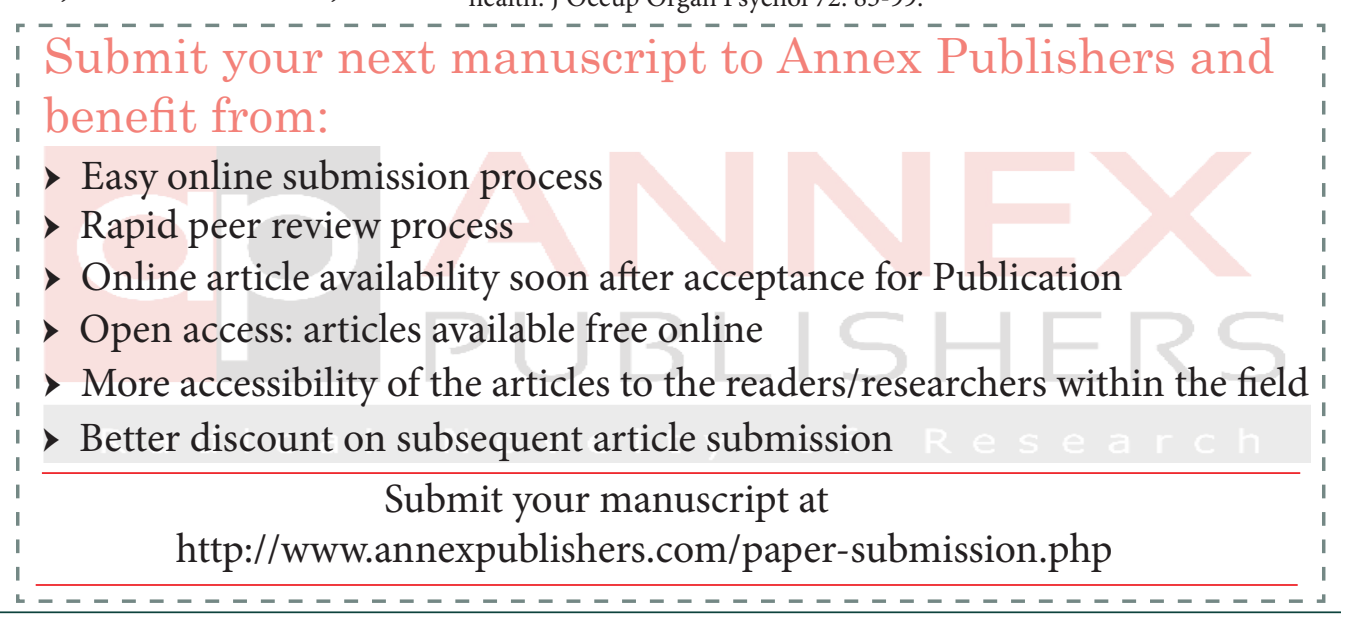

